\title{
CAPACIDADES DINÂMICAS E INOVAÇÃO COLABORATIVA: ESTUDO DE CASO NO SETOR TÊXTIL CATARINENSE
}

\section{RESUMO}

Com a concorrência cada vez mais acirrada, muitas firmas industriais de similares características preocupam-se com a obtenção de vantagens competitivas que permitam sua diferenciação para sobrevivência, eficiência e lucratividade. Usando como base a Teoria das Capacidades Dinâmicas (Eisenhardt \& Martin, 2000; Teece, 2007, 2014; Teece, Pisano, \& Shuen, 1997) a presente pesquisa buscou investigar como se desenvolvem as capacidades dinâmicas e a inovação colaborativa na manufatura de têxteis. Para tanto, desenvolveu-se um estudo de caso em uma empresa produtora de malhas, no qual se buscou analisar os processos de detecção de oportunidades direcionadas a inovação, a abordagem dessas oportunidades e o manejo de ameaças mediante a reconfiguração de recursos internos e externos à organização. Para triangulação, a coleta incluiu dados primários provindos de entrevistas semiestruturadas e dados secundários documentais e audiovisuais. A pesquisa identificou os seguintes processos na abordagem da inovação: 1) busca constante da melhor forma de selecionar clientes, de satisfazer e se antecipar as suas necessidades; 2) busca de inovação e melhora em produtos, processos e práticas e; 3 ) engajamento da liderança e equipes com a inovação. A contribuição deste trabalho reside na identificação, evidenciação empírica e análise dos processos envolvidos na Capacidade Dinâmica na perspectiva da inovação, oferecendo um modelo a seguir para análise dos processos vinculados a capacidades dinâmicas, facilitando a compreensão e constatação destas. Os resultados do estudo mostraram que ditas capacidades atuam não apenas como causa da inovação, mas também como consequência estabelecendo um ciclo virtuoso contínuo com orientação para a inovação colaborativa e dinâmica de produtos envolvendo o fabricante, os seus fornecedores e clientes permitindo a fidelização destes e sustentando uma vantagem competitiva no setor têxtil.

Palavras-chave: Gestão da Inovação, Estratégia de Inovação. Vantagem Competitiva. Classificação JEL O31, O32, L67.

\section{DYNAMIC CAPABILITIES AND COLLABORATIVE INNOVATION: A CASE STUDY IN THE TEXTILE INDUSTRY OF SANTA CATARINA, BRAZIL}

\section{ABSTRACT}

With increasingly fiercer competition, many industrial firms with similar characteristics are concerned with obtaining competitive advantages that allow them to differentiate themselves for survival, efficiency and profitability. Based on the Dynamic Capability Theory (Eisenhardt \& Martin, 2000; Teece, 2007, 2014; Teece, Pisano, \& Shuen, 1997), this research aimed to investigate how dynamic capacities and collaborative innovation in textile manufacturing are developed. To this end, a case study was conducted in a textile manufacturer, in which it was sought to distinguish the opportunities detection processes directed to innovation, the approach to these opportunities and the management of threats through the reconfiguration of internal and external organizational resources. For triangulation, data collection included primary data from semi-structured interviews and secondary documentary and audiovisual data. The research identified the following processes: 1) constant search for the best way to select clients, satisfy and anticipate their needs; 2) search for innovation and improvement in products, processes and practices; 3) leadership engagement and teams with innovation. The contribution of this work lies in the identification, empirical evidence and analysis of the processes involved in Dynamic Capability in the perspective of innovation, offering a model to analyze the processes linked to dynamic capacities, facilitating their understanding and verification. The results of the study showed that these capabilities act not only as a cause of innovation, but also as a consequence, establishing a continuous virtuous cycle oriented towards collaborative and dynamic innovation of products involving the manufacturer, its suppliers and customers, generating loyalty and sustaining a competitive advantage in the textile sector.

Keywords: Innovation Management. Innovation Strategy. Competitive advantage. JEL classification: O31, O32, L67. 


\section{CAPACIDADES DINÁMICAS E INNOVACIÓN COLABORATIVA: ESTUDIO DE CASO EN EL SECTOR TEXTIL CATARINENSE}

\section{RESUMEN}

Con la competencia cada vez más fuerte, muchas firmas industriales de similares características se preocupan por la obtención de ventajas competitivas que permitan su diferenciación para supervivencia, eficiencia y rentabilidad. La presente investigación buscó investigar cómo se desarrollan las capacidades dinámicas y la innovación colaborativa en la manufactura de los textiles. La base de la Teoría de las Capacidades Dinámicas (Eisenhardt \& Martin, 2000, Teece, 2007, 2014, Teece, Pisano, \& Shuen, 1997). Para ello, se desarrolló un estudio de caso en una empresa productora de mallas, en el que se buscó analizar los procesos de detección de oportunidades dirigidas a la innovación, el abordaje de esas oportunidades y el manejo de amenazas mediante la reconfiguración de recursos internos y externos a la gestión organización. Para triangulación, la recolección incluyó datos primarios provenientes de entrevistas semiestructuradas y datos secundarios documentales y audiovisuales. La investigación identificó los siguientes procesos en el enfoque de la innovación: 1) busca constantemente la mejor forma de seleccionar clientes, de satisfacer y anticiparse a sus necesidades; 2) búsqueda de innovación y mejora en productos, procesos y prácticas; 3 ) el compromiso del liderazgo y los equipos con la innovación. La contribución de este trabajo reside en la identificación, evidencia empírica y análisis de los procesos involucrados en la Capacidad Dinámica en la perspectiva de la innovación, ofreciendo un modelo a seguir para el análisis de los procesos vinculados a capacidades dinámicas, facilitando la comprensión y constatación de éstas. Los resultados del estudio mostraron que dichas capacidades actúan no sólo como causa de la innovación, sino también como consecuencia estableciendo un ciclo virtuoso continuo con orientación para la innovación colaborativa y dinámica de productos involucrando al fabricante, a sus proveedores y clientes permitiendo la fidelización de éstos y sosteniendo una ventaja competitiva en el sector textil.

Palabras clave: Gestión de la Innovación; Estrategia de Innovación; Ventaja Competitiva; Clasificación JEL O31, O32, L67.

\footnotetext{
${ }^{1}$ Doutoranda do Programa de Doutorado em Ciências Contábeis e Administração da Universidade Regional de Blumenau - PPGCC/FURB. Brasil. E-mail: jdemontre@yahoo.com

${ }^{2}$ Doutora em Administração pela Universidade Nove de Julho - UNINOVE. Professora do Programa de Doutorado em Ciências Contábeis e Administração da Universidade Regional de Blumenau - PPGCC/FURB. Brasil. E-mail: iaraparisotto@hotmail.com
} 


\section{INTRODUÇÃO}

Analisando as lutas competitivas de firmas em ambientes turbulentos percebeu-se a necessidade de um paradigma expandido para entender como se consegue e mantém a vantagem competitiva, tomando em conta que os ganhadores no cenário global, tradicionalmente são organizações que demonstram habilidade de resposta, inovação rápida e flexível e uma aptidão gerencial para coordenar efetivamente, desenvolvendo competências organizacionais internas e externas. (Teece, 2014; Teece et al., 1997).

Em uma perspectiva histórica, durante a década de 1980, a formulação de estratégias para consecução de vantagens competitivas foi norteada predominantemente pelo paradigma das forças competitivas. Neste modelo, cinco forças determinavam o potencial inerente em uma indústria: barreiras de entrada, ameaça de substituição, poder de barganha de compradores e fornecedores e rivalidade entre competidores do mesmo setor (Porter, 2015).

Prahalad e Hamel (2006) desenvolveram um conjunto de noções para identificar as raízes da vantagem competitiva: as capacidades centrais das empresas. Para esses autores, as capacidades são resultado de aprendizados coletivos das organizações, no processo de coordenação e diversificação da produção, ao integrar vários níveis de tecnologias, resultando na geração de valor para os consumidores.

No artigo Firm Resources and Sustained Competitive Advantage, Barney (1991) apontava que uma firma possuía uma vantagem competitiva sustentável, quando aquela era capaz de ter uma estratégia de criação de valor que não pudesse ser implementada ou duplicada por nenhum de seus concorrentes atuais ou potenciais. Para esse autor, a Visão baseada em Recursos (RBV) tem como premissa que a fonte de vantagem competitiva encontra-se nos recursos e capacidades desenvolvidas e controladas pelas organizações, devendo os recursos ser valiosos, raros, inimitáveis e não substituíveis (Barney, 1991).

Teece et al. (1997) ampliaram a RBV mediante a Teoria das Capacidades Dinâmicas, enfatizando a capacidade de renovação das estratégias alinhadas com as mudanças do ambiente de negócios e o papel da capacidade da gestão estratégica para adaptar, integrar e criar novos recursos e capacidades funcionais, com vistas a enfrentar o ambiente de inovação. (Nieves \& Haller, 2014; Teece, 2007, 2014; Teece et al., 1997). As capacidades dinâmicas podem ser processos específicos, melhores práticas ou competências que refletem a eficácia em mercados de alta velocidade e guiadas por mecanismos de aprendizagem (Eisenhardt \& Martin, 2000), permitindo criar, estender e modificar a base de conhecimentos para responder a mudanças no ambiente de negócios. (Adner \& Helfat, 2003; Zollo \& Winter, 2002).
Contrários a esta teoria mencionam que as capacidades dinâmicas são descritas na literatura como abstratas, imprecisas, ocultas ou difíceis de observar e mensurar e causalmente ambíguas. Além disso, que sob o mesmo rótulo de 'capacidades dinâmicas' tenta-se se agrupar uma série de conceitos heterogêneos e difusos, sendo essas difíceis de reconhecer na prática, contandose assim com pouca evidencia empírica de suporte. (Pavlou \& El Sawy, 2011; Verona \& Ravasi, 2003).

Outra fonte de vantagem competitiva provém da capacidade das organizações de combinar sua expertise com os inputs das redes, tanto de clientes como de fornecedores e parceiros, facilitando a comunicação, melhorando as interações e relacionamentos, a coordenação e inovação colaborativa, permitindo a aquisição de valor adicionado superior ao alavancar o conhecimento e o acesso direto e indireto a mercados, tecnologia e outras fontes de vantagens competitivas (Saenz \& Revilla, 2014). Os grupos colaborativos contribuem para atualizar e reforçar as fontes de conhecimento (Nonaka, 2008; Subramaniam \& Youndt, 2005). Calamel, Defélix, Picq, \& Retour (2012) apontam a necessidade de investigar a colaboração, que permite examinar o suporte gerencial e as motivações dos atores para cooperar.

Assim, esta pesquisa pretende resolver esta lacuna respondendo complementarmente aos estudos de Teece $(2007,2014)$ e Teece, Pisano e Shuen (1997) a seguinte questão: como se desenvolvem as capacidades dinâmicas e a inovação colaborativa na manufatura de produtos têxteis? $O$ objetivo deste estudo foi contribuir à compreensão sobre capacidades dinâmicas e inovação colaborativa no setor têxtil, utilizando para tal um estudo de caso pautado pela abordagem de Eisenhardt (1989).

Os dados primários provêm de uma indústria de tecidos de malha, situada na cidade de Jaraguá do Sul, SC. A coleta de dados envolveu várias fontes de dados: entrevistas semiestruturadas, realizadas com pessoal da empresa e informação do site institucional, como portfólio de produtos e vídeos institucional e de clientes. A triangulação de dados qualitativos deu-se pela variedade das fontes de dados e pela codificação e interpretação, com participação de dois pesquisadores, no processo de estabelecimento de conexões com a literatura (Bernard \& Gravlee, 2014).

A escolha do caso pautou-se por seleção intencional de uma organização atuante no mercado nacional e internacional, em um Estado eminentemente têxtil como Santa Catarina (SINTEX, 2015). Dados do Sindicato das indústrias de fiação, tecelagem e do vestuário de Blumenau (SINTEX) atestam que atualmente a participação de Santa Catarina tem no segmento têxtil é de $27 \%$ do total nacional, liderando o ranking das exportações brasileiras de vestuário no Brasil, sendo os maiores destaques, os polos produtores de malharia e beneficiamento, nos quais participa com 
$36,8 \%$ da produção total de tecidos de malha e $29,5 \%$ da produção nacional de artigos beneficiados (SINTEX, 2015).

A contribuição deste trabalho reside na identificação, evidenciação empírica e análise dos processos envolvidos na Capacidade Dinâmica na perspectiva da inovação. Dentre esses processos foram identificados: 1) A busca constante da melhor forma de selecionar clientes, de satisfazer e se antecipar as suas necessidades; 2) A busca de inovação e melhora em produtos, processos e práticas e; 3) $\mathrm{O}$ engajamento da liderança e equipes com a inovação.

Este estudo foi estruturado por quatro seções além desta introdutória. $\mathrm{Na}$ seguinte seção, é apresentado o referencial teórico sobre os tópicos referentes à Teoria das Capacidades Dinâmicas, determinantes da inovação e inovação colaborativa. A seguir, apresentaram-se os procedimentos metodológicos, seguindo com a discussão dos resultados. Por fim, foram feitas as considerações finais.

\section{FUNDAMENTAÇÃO TEÓRICA}

\section{Teoria das Capacidades Dinâmicas (TCD)}

Sustentar uma vantagem competitiva estratégica requer o desenvolvimento de capacidades dinâmicas (Rumelt, Schendel, \& Teece, 1994; Teece, 2007). Teece, Pisano e Shuen (1997) se referem às capacidades dinâmicas ressaltando dois aspectos que não levaram grande atenção em perspectivas teóricas anteriores: a "competência", ou a capacidade da gestão estratégica em adaptar, integrar e combinar recursos e funções para enfrentar um ambiente de mudanças. E, em segunda instância, o "dinamismo", que se relaciona com a capacidade de renovar capacidades oportunamente, em tempos de mudanças tecnológicas rápidas e quando a natureza da concorrência potencial é difícil de determinar.

Zollo e Winter (2002, p. 5) definem a capacidade dinâmica como um "padrão aprendido e estável de atividade coletiva mediante o qual a organização sistematicamente gera e modifica as rotinas operativas em busca de eficiência melhorada". Augier e Teece $(2009$, p. 412) acrescentam que esta inclui "a capacidade de perceber e em seguida, aproveitar novas oportunidades e reconfigurar e proteger ativos de conhecimento, capacidades e ativos complementares".

Eisenhardt e Martin (2000) salientam que as capacidades dinâmicas são específicas tanto para organizações como para processos e são influenciadas pelo dinamismo do mercado, não sendo sempre previsíveis. Esses autores salientam que as capacidades dinâmicas são um conjunto de processos identificáveis e específicos como desenvolvimento de produtos, decisão estratégica e alianças, que são condições necessárias, mas não suficientes para gerar vantagem competitiva.

Em nível empresarial, a empresa deve fazer mais que simplesmente destinar grandes recursos de P\&D para manter um desempenho superior. O processo de inovação requer de uma coordenação ativa de recursos intangíveis e tangíveis de parte de empreendedores e gestores, sem importar o tamanho da organização. A abordagem de capacidades dinâmicas permite manter a superioridade durante o tempo ao estimular para que as firmas modifiquem sua base de recursos para se adaptar a condições de mudança. A compreensão desta orquestração é o ponto central da teoria das capacidades dinâmicas (Augier \& Teece, 2009; Nieves \& Haller, 2014).

O modelo de Teece $(2007,2014)$ estabelece que a vantagem competitiva reside nos processos e rotinas gerenciais e organizacionais determinados pela disponibilidade específica (ou posição) dos ativos e os percursos necessários para consegui-los (trilhas). A posição tem a ver com a tecnologia, ativos complementários, base de clientes e relações externas com fornecedores e complementadores. As trilhas referem-se às alternativas estratégicas disponíveis para a firma e a presença ou ausência de retornos crescentes.

Teece $(2007,2014)$ desagrega as capacidades dinâmicas em três componentes ou momentos: $\mathrm{O}$ primeiro que se relaciona com a detecção de oportunidades e ameaças, que inclui os processos direcionados para inovação, incluindo a identificação de mercados alvo e novas necessidades de clientes; o segundo, que foca-se na abordagem das oportunidades, que visam propor modelos de negócios para clientes, construindo a lealdade destes e o terceiro, composto pela combinação, reconfiguração das capacidades. $\mathrm{Na}$ Figura 1, uma síntese da proposta da TCD. 
Figura 1 - Teoria das Capacidades Dinâmicas

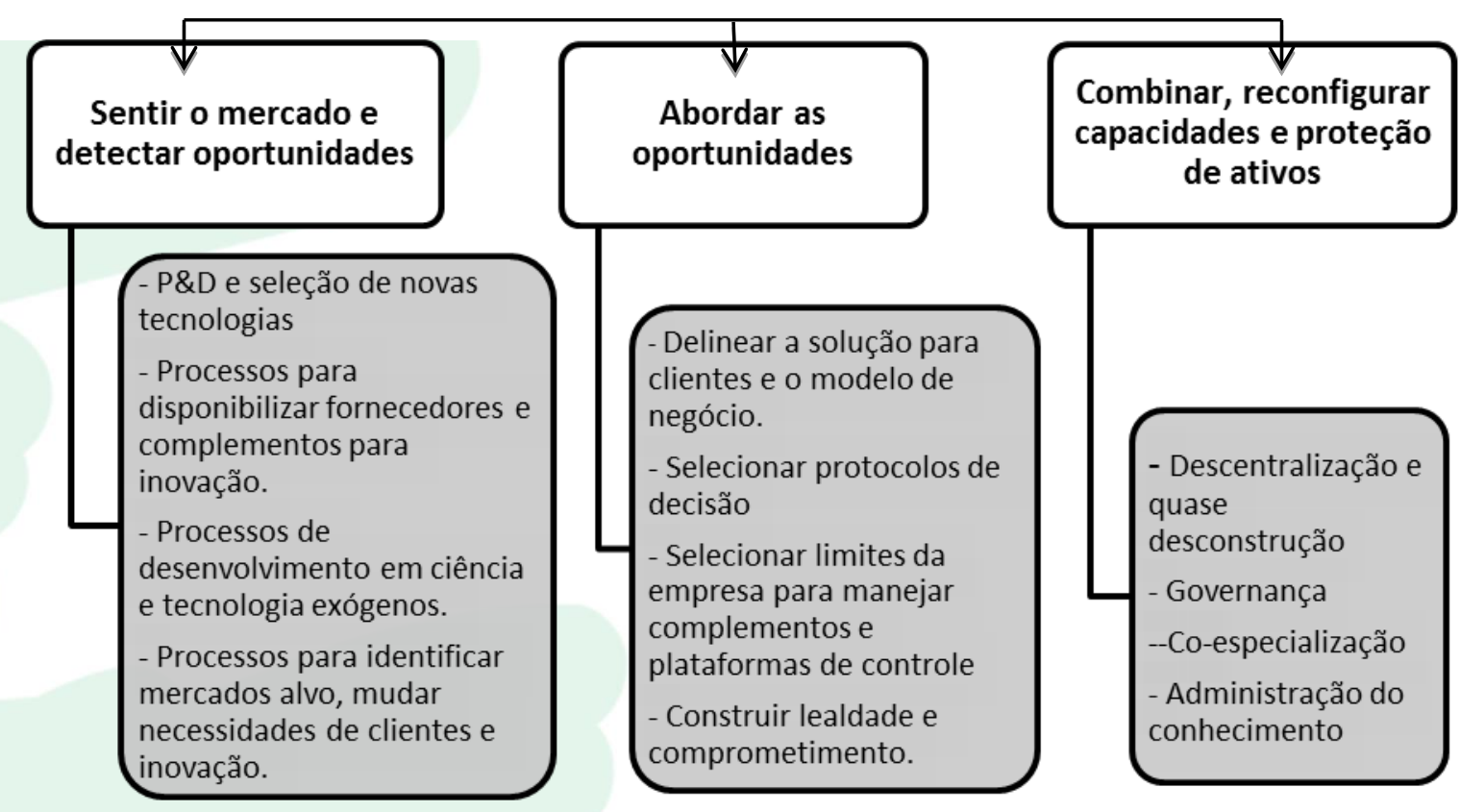

Fonte: Adaptado de Teece (2007).

Em ambientes de negócios globalizados e caracterizados pela dispersão geográfica das fontes de inovação e manufatura, a vantagem competitiva sustentável precisa mais do que a posse de ativos dificilmente imitáveis, mas também de capacidades dinâmicas únicas e difíceis de replicar que possam criar, estender, atualizar, proteger e conservar a base de ativos únicos da empresa (Teece, 2007).

\section{Determinantes da Inovação}

Poucos assuntos contam com tanto consenso como o papel da inovação no desenvolvimento econômico e social. A inovação contribui com o crescimento econômico, a performance organizacional, sendo central para a evolução de produtos e produtividade das organizações (Hult, Hurley, \& Knight, 2004; Schumpeter, 1961; Van de Ven, 1986; Volberda, Van Den Bosch, \& Mihalache, 2014).

De maneira abrangente, a inovação pode ser definida como a "produção, adoção, assimilação ou exploração de novidade com valor agregado econômico e social, renovação e melhoria de produtos, serviços e mercados; novos métodos de produção e sistemas de gestão" (Crossan \& Apaydin, 2010, p. 1155), sendo considerada tanto um processo, como um resultado.

Van de Ven (1986) define inovação como o desenvolvimento e implementação de novas ideias por parte de pessoas envolvidas em transações, durante um lapso de tempo determinado e dentro de certo contexto institucional, envolvendo quatro questões básicas: a gestão de pessoas, a gestão de novas ideias, as relações "parte-todo" e a liderança institucional. O autor ressalta que as ideias inovadoras são uma atividade individual, porém, a inovação é um processo coletivo, de apreender essas ideias e direcioná-las para a produção.

A inovação como processo dinâmico se baseia na criatividade para desenvolver novas ideias referidas a produtos, serviços, processos e procedimentos, assimilando os conceitos existentes de uma forma nova, sendo a dinâmica da inovação descrita mediante um ciclo que evolui em torno à criatividade, inovação e mudança, que não é usualmente um processo linear (Zhuang, 1995).

Damanpour (1991) analisa a relação entre inovação organizacional e os seus potenciais determinantes, tais como especialização, diferenciação, profissionalismo, centralização, atitude gerencial, intensidade administrativa, escassez de recursos e comunicação externa e interna. Esse autor assevera que a adoção de inovações é concebida para abranger a geração, desenvolvimento e a implementação de novas ideias e comportamentos. Dessa forma, uma inovação pode ser um novo produto ou serviço, geralmente gerado com a intensão de contribuir no desempenho e a efetividade da organização que o adota. Mais que uma resposta às mudanças, a inovação é um meio para mudar a organização.

$\mathrm{Na}$ busca dos padrões de ideias que emergem nas firmas e que têm um papel central na moldagem das organizações inovadoras, Blau, Mckinley e Blau (2008) analisaram os processos sociais formais e informais que encontrando algumas dimensões básicas organizacionais, tais como complexidade estrutural, de 
tarefas e inovação bem-sucedida. Os autores consideraram que os membros das organizações são afetados pelos procedimentos organizacionais, propósitos oficiais e outras pressões organizacionais, mesmos que também os definam como construtores ativos dos seus arranjos sociais.

Christensen, Suárez e Utterback (1998) ponderam que o comportamento ligado à escolha dos gestores, influi poderosamente na sobrevivência e evolução das firmas, em um grau ainda maior que o ambiente externo. Em um ambiente de inovação, os gestores com atitudes favoráveis para a mudança direcionam o clima interno direcionando-o para inovação. Portanto, o suporte para inovação é requerido na fase de implementação da inovação, quando a coordenação e solução de conflitos entre indivíduos e unidades tornam-se essenciais (Damanpour, 1991).

Amabile, Conti, Coon, Lazenby e Herron (1996) manifestam que a determinação para o sucesso da inovação se relaciona ao encorajamento da organização para o sucesso dos projetos inovadores em nível de chefia, supervisão e grupos de trabalho, aceitando os riscos e valorizando a inovação em todos os níveis hierárquicos. Também se relaciona com a avaliação e suporte de novas ideias, recompensa e reconhecimento da criatividade e liderança participativa e colaborativa.

Christensen, Craig e Hart (2001) consideram que existem quatro razões para os bons gestores tomarem precauções sobre a implementação de inovações: primeiro, porque as companhias líderes consideram que elas não conquistam clientes valiosos no começo. Segundo, porque as tecnologias adotam novos produtos e serviços com um impacto no mercado que não pode ser facilmente medido nem predito. Terceiro, os gerentes se focam no lucro e as tecnologias disruptivas oferecem produtos mais baratos com menores lucratividades. Finalmente, as companhias líderes buscam grandes mercados e os mercados emergentes para inovações são pequenos no começo, não oferecendo grandes volumes de negócios.

$\mathrm{Na}$ análise da dinâmica e da relação multinivel entre a inovação e a organização, Lam (2004) distingue três perspectivas que, embora diferentes, poder ser consideradas interdependentes: a primeira relaciona a forma estrutural da organização e a sua capacidade inovadora, a segunda, considera o processo de aprendizagem organizacional e a criação de conhecimento e sua inovatividade, e a terceira, a capacidade da organização para mudança e adaptação. Lam (2004) argumenta que inovação organizacional deve ser uma condição necessária para uma inovação tecnológica enfatizando o papel das variáveis endógenas (capacidade para aprender, valores, interesses e poder) para moldar a transformação organizacional e tecnológica.

Klein \& Knight (2005) sugerem que existem seis fatores que determinam o processo e os resultados da inovação. $O$ primeiro se relaciona às políticas e práticas de implementação da inovação cuja influência é acumulativa e compensatória, que inclui a qualidade e a quantidade de treinamento disponível para os empregados, a provisão de assistência técnica aos usuários da inovação, avaliação de recompensas para uso de inovação e qualidade e acessibilidade da tecnologia. Um segundo fator crítico é o clima da organização ou equipe, que tem a ver com as percepções da importância da inovação na organização.

$\mathrm{O}$ terceiro fator envolve o papel dos gestores no suporte da inovação. O quarto, a disponibilidade de recursos financeiros para implementação, treinamento, suporte e introdução dos projetos inovadores. O quinto é a orientação para a aprendizagem que consiste nas práticas inter-relacionadas e crenças que suportam e possibilitam o desenvolvimento de capacidades organizacionais e individuais. Finalmente, o último fator crítico é a orientação em longo prazo dos gestores. Eles devem compreender que o processo de implementação da inovação pode trazer benefícios em longo prazo, mesmo que diminua a produtividade e eficiência no curto prazo (Klein \& Knight, 2005).

\section{Inovação Colaborativa}

Para Brown e Eisenhardt (1995) uma importante vertente de pesquisa em inovação e desenvolvimento de produtos centra-se na comunicação entre os agentes de inovação, sendo a premissa que a comunicação interna entre os membros das equipes e externa incluindo elementos externos, estimula o desempenho das equipes, o que quer dizer que quanto melhor conectados interna e externamente, melhor sucedidos serão os produtos desenvolvidos.

Jassawalla e Sashittal (1999) apontam que existe pouca disputa de que a integração multifuncional melhora o processo de desenvolvimento de produtos. Interações de alta qualidade e coordenação entre departamentos como $\mathrm{P} \& \mathrm{D}$, produção, marketing $\mathrm{e}$ outros grupos funcionais incrementa a criatividade, reduz custos e acelera o ciclo de desenvolvimento de produtos. Para garantir esses resultados, os gestores experimentam com arranjos estruturais, estruturas matriciais de projeto e produto e equipes de engenharia concorrentes. Isto para garantir que as capacidades coletivas da organização sejam refletidas nos produtos novos.

De acordo com Brown e Eisenhardt (1995) a pesquisa sobre a participação de elementos externos à organização na contribuição com o processo de inovação de produtos e criação de valor inicia-se na década de 1970, focando-se principalmente na comunicação externa das equipes de P\&D (Allen, 1971), a análise da relação da comunicação das equipes de inovação com o ambiente externo e a performance superior dos projetos de inovação (Katz \& Tushman, 1981) e a comunicação com clientes chave para desenvolvimento de melhores produtos (Von Hippel, 1986). 
O envolvimento de equipes externas em desenvolvimento de produtos implica abertura da inovação. Para Baldwin e Von Hippel (2011) uma inovação é aberta quando a informação relacionada à inovação torna-se um bem público, sem restrições de competência ou exclusão. $\mathrm{O}$ uso do termo foi inicialmente ligado à indústria do software livre, ampliando-se posteriormente a sua aplicação para outros setores.

Por muito tempo, teóricos da economia recomendaram restrições na abertura da informação sobre inovação, pois vazamentos de conhecimento não recompensados poderiam reduzir os ganhos dos investidores privados, desencorajando a atratividade dos investimentos. No entanto, a pesquisa empírica mostra que muitos indivíduos e firmas inovadores revelam livre e voluntariamente o que desenvolvem, outorgando acesso e direitos de propriedade a todas as partes interessadas (Baldwin \& Von Hippel, 2011).

A literatura acadêmica suporta que a inovação colaborativa se vincula também aos fornecedores. Corsten e Felde (2005) asseveram que a colaboração dos fornecedores tem efeitos positivos no comportamento dos compradores e nos resultados financeiros da parceria. Os fornecedores podem contribuir com a inovação das firmas absorvendo custos de P\&D que normalmente impactariam nos clientes. De fato, os fornecedores têm conhecimento da produção podendo transferir ideias para produzir melhores produtos. A colaboração do fornecedor facilita o compartilhamento de conhecimento tácito e explícito, melhorando a criação de conhecimento e a capacidade de inovação do cliente.

Os comportamentos colaborativos acontecem quando os participantes possuem necessidades intrínsecas de experimentação e aprendizagem concordando com uma agenda comum, assim como compartilham abertamente desafios e poder, comprometendo-se e construindo confiança mútua, e em menos proporção, como resultado de diretrizes da alta gestão (Jassawalla \& Sashittal, 1999).

\section{MÉTODO}

A pesquisa, quanto ao seu objetivo foi caracterizada como um estudo de caso, com uso de dados documentais audiovisuais e de entrevistas semiestruturadas realizadas com membros da equipe de P\&D e comercialização, de uma empresa têxtil catarinense. O estudo de caso seguiu a abordagem indutiva de teoria (Eisenhardt, 1989), sendo este método usado quando deliberadamente abordam-se condições contextuais, acreditando que podem estar relacionadas ao fenômeno em estudo (Yin, 2015).

\section{Estudo de caso}

Para análise das capacidades dinâmicas vinculadas aos processos de inovação, a escolha do caso foi norteada por seleção intencional (Bernard \& Gravlee, 2014), com escolha de uma firma com mais de 20 anos no mercado, de grande porte (SEBRAE, 2016), Possui várias instalações fabris, atuante no mercado doméstico e internacional mediante exportação e no qual se pudesse ter acesso a informantes-chave (Guest, 2014) em pelo menos duas unidades de negócio diferentes em um Estado eminentemente têxtil como Santa Catarina (SINTEX, 2015).

\section{Sujeitos de Pesquisa}

O processo de escolha dos sujeitos na pesquisa qualitativa difere da amostragem na pesquisa quantitativa, no sentido de que o objetivo é distinto e com foco na compreensão do fenômeno (Maykut \& Morehouse, 2002), sendo o número apropriado de sujeitos em um estudo qualitativo, aquele que impeça a redundância e a saturação no processo de resposta adequada da pergunta de pesquisa (Trotter, 2012). No presente trabalho, os sujeitos de estudo foram funcionários das áreas de inovação e criação, comercialização e atendimento de uma empresa têxtil, com instalações fabris nas cidades de Jaraguá do Sul e Presidente Getúlio, SC. A seleção dos sujeitos deu-se de modo intencional.

\section{Coleta de Dados}

O corpus (Aarts \& Bauer, 2002) desta pesquisa proveio de três entrevistas semiestruturadas realizadas com a equipe responsável da área de inovação, coletadas em visita à unidade fabril, localizada na cidade de Jaraguá do Sul, SC e realizadas em Dezembro de 2015; ademais, de informações disponíveis no site institucional e de material audiovisual selecionado: 1 vídeo institucional e 6 vídeos contendo depoimentos de clientes da empresa com os que acontece a parceria e colaboração no design de malhas, conforme apresentado na Tabela 1. $\mathrm{O}$ protocolo da entrevista semiestruturada para aplicação da entrevista se elaborou tomando como base a literatura consultada, conforme Apêndice. 
Tabela 1 - Composição do Corpus da Pesquisa

\begin{tabular}{|c|c|c|c|c|}
\hline Fonte & Tipo de Fonte & Materiais & Sujeito & $\begin{array}{l}\text { Duração } \\
\text { (mm/seg.) }\end{array}$ \\
\hline \multirow{7}{*}{ A EMPRESA } & \multirow{4}{*}{ Primária } & \multirow{5}{*}{$\begin{array}{l}\text { Entrevistas } \\
\text { Semiestruturadas }\end{array}$} & $\begin{array}{l}\text { Responsável } \quad \text { P\&D } \\
\text { Inovação, profissional em } \\
\text { design e técnico em moda }\end{array}$ & $31 \mathrm{~min} .50 \mathrm{seg}$. \\
\hline & & & $\begin{array}{l}\text { Responsável } \quad \mathrm{P} \& \mathrm{D} \\
\text { Inovação, profissional em }\end{array}$ & $32 \mathrm{~min} .31 \mathrm{seg}$. \\
\hline & & & Responsável de & \\
\hline & & & $\begin{array}{l}\text { atendimento } \\
\text { comercialização }\end{array}$ & $41 \mathrm{~min} .08 \mathrm{seg}$. \\
\hline & & & Profissional em marketing & \\
\hline & $\begin{array}{l}\text { Secundária } \\
\text { Informações Institucionais, }\end{array}$ & $\begin{array}{l}\text { Vídeo } \\
\text { Institucional }\end{array}$ & Dalila Têxtil & $03 \mathrm{~min} .35 \mathrm{seg}$. \\
\hline & portfólio de produtos. & Site Institucional & Dalila Têxtil & --- \\
\hline \multirow{6}{*}{ CLIENTES } & \multirow{6}{*}{$\begin{array}{l}\text { Secundária } \\
\text { Os vídeos contêm } \\
\text { depoimentos de clientes } \\
\text { sobre a vivência do } \\
\text { trabalho conjunto com a } \\
\text { Dalila Têxtil }\end{array}$} & Vídeo 1 & Biotwo & 02 min. 23 seg. \\
\hline & & Vídeo 2 & Martin Negra & $01 \mathrm{~min} .44 \mathrm{seg}$. \\
\hline & & Vídeo 3 & Storvo & $02 \mathrm{~min} .29 \mathrm{seg}$. \\
\hline & & Vídeo 4 & Beagle & 02 min. 43 seg. \\
\hline & & Vídeo 5 & Limits & 02 min.16 seg. \\
\hline & & Vídeo 6 & Oceano & 03 min. $15 \mathrm{seg}$. \\
\hline \multicolumn{4}{|l|}{ Total } & $123 \mathrm{~min} .54 \mathrm{seg}$ \\
\hline
\end{tabular}

Fonte: Dados da Pesquisa (2017).

\section{Análise de dados}

A técnica utilizada foi a de análise de conteúdo, mesma que de acordo com Flick (2009, p. 203) inclui basicamente três momentos: "abreviação da análise do conteúdo, análise explicativa do conteúdo e análise estruturadora do conteúdo". No presente trabalho, a análise foi realizada com auxilio do software de pesquisa qualitativa QSR NVivo v.10® para análise de conteúdo, incluindo a codificação, classificação e hierarquização dos dados resultantes das transcrições de todos os materiais coletados e enumerados na tabela $\mathrm{N}^{\circ} .1$.

Para esse estudo, foram selecionadas categorias provindas do modelo de Teece (2007), conforme Quadro 1.

\begin{tabular}{l|l|l}
\hline $\begin{array}{l}\text { Sentir o mercado e detectar as } \\
\text { oportunidades no Processo de Inovação }\end{array}$ & $\begin{array}{l}\text { Abordar oportunidades - } \\
\text { Clientes / Mercados }\end{array}$ & $\begin{array}{l}\text { Combinação e Reconfiguração } \\
\text { de Capacidades }\end{array}$ \\
\hline • Projetos e ideias inovadoras. & $\bullet$ Mercados Alvo & $\bullet$ Liderança \\
- Pesquisa e Desenvolvimento (P\&D) & $\bullet$ Clientes & $\bullet$ Governança \\
• Envolvimento dos funcionários & $\bullet$ Lealdade. & $\bullet$ Administração do \\
- Inovação Externa & & Conhecimento. \\
\hline
\end{tabular}

Quadro 1 - Síntese das Categorias da Pesquisa

Fonte: Elaborado pelos autores (2017)

Durante a análise de dados, diversas categorias e subcategorias foram classificadas e categorizadas e realizada a codificação, cobrindo todas as unidades temáticas identificadas no Quadro 1 e emergentes nas entrevistas (Eggers \& Kraus, 2012). O roteiro de entrevistas apresenta-se no Apêndice.

\section{RESULTADOS E DISCUSSÃO}

\section{Apresentação do Caso}

A Dalila Têxtil foi fundada em 1992 com o propósito de oferecer malharia diferenciada e soluções específicas conforme as demandas de confeccionistas e criativos da indústria da moda, que na atualidade compõem uma lista de mais de dois mil clientes. $\mathrm{Na}$ Figura 2 algumas imagens do parque fabril (Dalila Têxtil, 2017) 
Figura 2 - Vistas do setor de produção

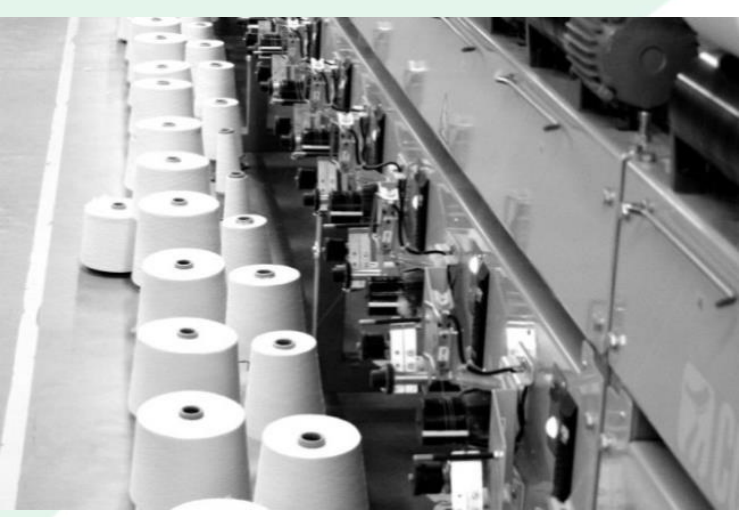

Conicaleira - Repasse de Fios

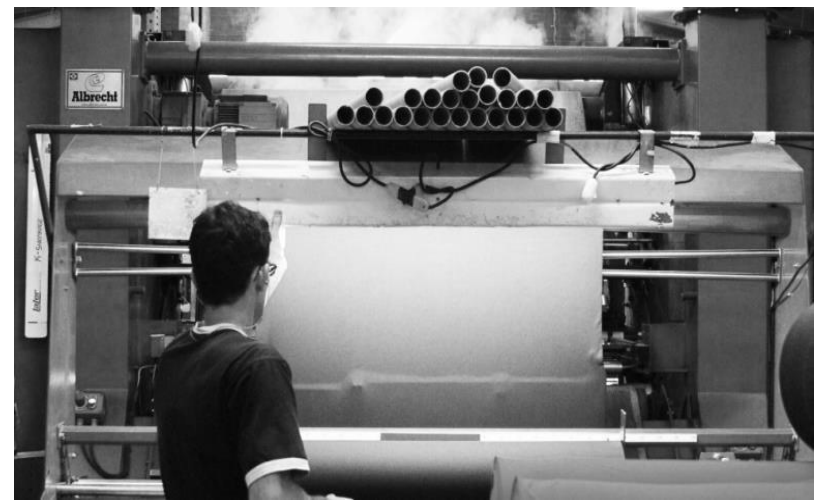

Calandra Tubular - Acabamento Tinturaria

Fonte: Site institucional Dalila Têxtil (2017).

O parque fabril desta empresa conta com mais de $25.000 \mathrm{~m}^{2}$ de área construída em duas unidades fabris, localizadas nas cidades de Jaraguá do Sul e Presidente Getúlio, Estado de Santa Catarina, com uma capacidade produtiva de 600 toneladas/mês, 550 colaboradores e máquinas de tecnologia de ponta, apoiadas por sistemas de automação de última geração (Dalila Têxtil, 2017).

\section{Ambiente de design}

A "Casa Rosa" é um ambiente de design separado da fábrica, local onde se desenham e cocriam tecidos. Também é o lugar de atendimento de clientes, no qual se discutem conjuntamente as necessidades destes avaliando a capacidade da empresa para produzir os tipos de tecidos solicitados, produzindo amostras de tecidos que serão avaliadas para a produção final. A continuação, imagens da unidade fabril em Jaraguá do Sul e do ambiente de design denominado a Casa Rosa (Dalila Têxtil, 2017).

Figura 3 - Fotografias Dalila Têxtil

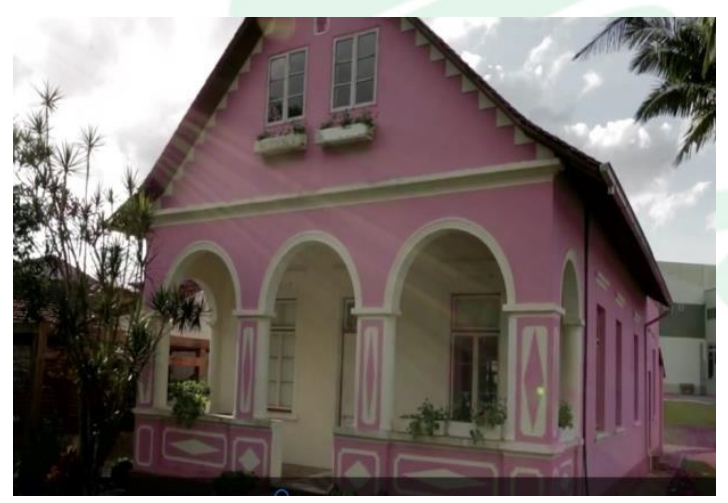

A Casa Rosa (ambiente de design)

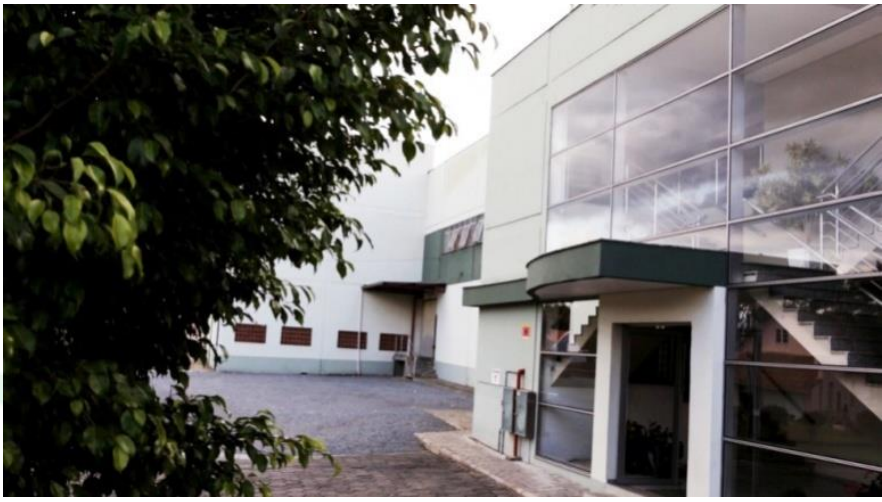

Unidade Fabril em Jaraguá do Sul, SC

Fonte: Site Institucional Dalila Têxtil (2017).

\section{Clientes}

A empresa conta com uma média de 2000 clientes ativos, dos quais selecionou aproximadamente 90 para oferecer produtos diferenciados e soluções específicas, conforme as demandas destes. A empresa também possui uma rede de 34 representantes em 18 estados do Brasil, e internacionalmente, no Paraguai, Uruguai e Bolívia (Dalila Têxtil, 2017).

\section{Linhas de produtos}

A empresa produz malhas em rolo de tipo liso e também malhas estruturadas do tipo Piquet, moletom, meia malha. A cada temporada a Dalila lança cerca de 200 produtos novos, que são produzidos para venda ao atacado e varejo. Além disso, a empresa fabrica malha Premium, para moda masculina, tecidos que são cocriados exclusivamente com cada marca. A empresa também produz duas linhas de malhas feitas com fibras recicladas e alternativas: 
a) Linha Infinity®: produzida com fibra produto do desfibrado, cujo processo nasce da recuperação dos retalhos da confecção convencional. O desfibrado consiste em desfiar o retalho até ele ter a capacidade de virar uma fibra para produzir uma malha integra, tanto na sua construção como no resultado final. A linha Infinity economiza em torno de $80 \%$ da água necessária para o processo de produção e tinturaria.

b) Recycle line®: Para produzir as peças desta linha, a empresa compra os fios derivados da fibra da garrafa PET e confecciona as malhas, que podem ser $100 \%$ das fibras alternativas ou misturadas a outras. A roupa feita a partir do plástico não é diferente da convencional, seja no corte, caimento ou textura, as quais nada lembram uma garrafa de plástico.

\section{Análise de conteúdo do caso}

A seguir, uma breve descrição das unidades temáticas identificadas na literatura e nos dados, agrupadas em três classes, evidenciadas no corpus desta pesquisa.

a) Busca constante da melhor forma de selecionar clientes, de satisfazer e se antecipar as suas necessidades.

- Identificação de mercados alvo: A Dalila tem se focado desde 2012 em clientes específicos: grifes, gestores de moda, confeccionistas, estilistas e designers, para quem oferece um leque de produtos diferenciados, a partir da fabricação da malha Premium exclusiva para moda masculina, desenvolvida especialmente de acordo com as diretrizes de cada cliente, com qualidade da tinturaria, variedade de cores e de texturas.

Dalila tem um leque de tecidos maravilhoso, desenvolvido para nós. É importantíssimo isso ai, desenvolver algo novo. Sempre prestando essa atenção. A tinturaria da Dalila é realmente fantástica. Porque se o tecido é legal, mas se a tinturaria não é boa, então não vai funcionar (Depoimento M. Negra).

- Atenção às necessidades de clientes na inovação de produtos e respeito à característica diferencial de cada cliente: os materiais são criados a pedido específico do cliente. Os produtos nascem de ideias que tem a ver com o conceito da marca do cliente e a sua visão para a coleção da estação. Para o processo de inovação colaborativa de tecidos, o cliente e o pessoal da fábrica se concentram no ambiente de design denominado Casa Rosa, processo que termina com a fabricação e entrega de amostras. Quando aprovado, os rolos são tecidos.

Outro diferencial é que a gente trabalha uma criação compartilhada. Então tudo na Dalila é o cliente, a gente não faz nada sozinha (Responsável de $\mathrm{P} \& \mathrm{D})$.

$O$ nosso produto ele nasce sempre a través de uma ideia que tem que ver com o conceito da nossa marca que é nessa linha de perturbação, tudo a ver com o nome Storvo, que tem a ver com o slogan nosso que é "keep disturbing". A gente gosta muito de trabalhar sempre com a melhor qualidade e a Dalila foi um elemento fundamental nesse processo, porque eles têm a linha peletizada, porque a gente acha que o toque na peça faz toda diferença no produto final $e$ agrega muito valor ao produto (Depoimento da Storvo).

- Atendimento acolhedor em espaço de design: o fabricante ouve o que o cliente solicita e propõe opções a partir disso. A empresa entende que o processo de criação não tem separação com o de relacionamento com o cliente, seja na fábrica ou no local do cliente, portanto, a dedicação do espaço de design e disponibilização de pessoas para o atendimento acolhedor faz o diferencial desta com outras empresas do setor.

Isso, a gente escuta o que o cliente quer, e propõe coisas encima disso. Então a gente faz tudo compartilhado, a gente tem um diferencial que a gente chama de atendimento acolhedor. Ai o cliente vem para cá, a Casa Rosa, é o nosso setor de relação e criação. Então a gente entende que a criação não é separada de uma boa relação (Responsável de $\mathrm{P} \& \mathrm{D})$.

- Acompanhamento da inovação externa do setor: O relacionamento estreito com os clientes faz com que possam fluir comunicações acerca do movimento dos concorrentes. Também se monitora informações de fornecedores a respeito de novos insumos e maquinário.

As empresas concorrentes? É mais pelo que os clientes falam. Assim, quando a gente leva nossa coleção para eles, ai eles falam, ah, tal empresa fez isso, tal empresa fez aquilo... (Responsável de atendimento e comercialização). 
- Inovação orientada à cooperação com clientes e fornecedores: o processo criativo de cada coleção começa com uma viagem de pesquisa aos centros internacionais da moda, na Europa, Estados Unidos, Ásia, etc. para verificar as tendências mundiais. A equipe que viaja tem conhecimentos profundos das capacidades de fabricação e do processo produtivo da empresa. As peças adquiridas na viagem são logo enviadas para os diversos clientes, que se posicionam sobre as peças. A empresa coleta todas essas opiniões de acordo com cada tendência, tanto no Brasil, como com os representantes internacionais. Todo ano a empresa organiza duas convenções de vendas com os clientes. Posteriormente se incorporam os materiais e opiniões provindos dos fornecedores. A criação da coleção assim unifica as tendências de fora e dentro do país, a opinião dos confeccionistas e estilistas, a colaboração dos fornecedores e do pessoal da fábrica, que dará a palavra final do que realmente poderá ser feito com a infraestrutura industrial existente.

Na Dalila você tem um espaço para você criar a sua própria base esse diferencial é extremamente importante. A gente pode experimentar algo novo juntos, algo novo que a gente estava buscando como o novo que a Dalila oferece (Depoimento Limits).

b) Busca de inovação e melhora em produtos, processos e práticas

- Estratégias para abordagem de competitividade em ambiente de constantes mudanças: a empresa desenvolve suas estratégias em várias frentes: inovação de produtos a cada coleção, inovação de processos e práticas voltadas para inovação. Desenvolvimento de capacidades de criação de conhecimento mediante especialização, atitude da equipe gestora e comunicação e integração entre as equipes multidisciplinares.

- Processo constante de comunicação com clientes - a empresa utiliza-se de três formas para comunicar-se com seus clientes. Como primeira forma, os clientes visitam a Casa Rosa, a segunda, as visitas ao cliente e a terceira, mediante um contato direto ou com o representante.

A gente tem 3 maneiras: uma quando os clientes vêm para cá. A gente muda a estrutura da casa para atender cada cliente, no sentido de... a gente já sabe mais ou menos o que eles vêm buscar aqui, então a gente já deixa algumas coisas mais à mão, outras mais... Enfim, preparadas para receber ao cliente (Responsável de P\&D).

- Compromisso com a inovação constante (a cada coleção): a busca de inovação desta empresa têxtil significa a busca de novos fios, cores, estruturas e materiais. Também observa-se este compromisso nos pequenos detalhes, seja no processo produtivo, seja na apresentação ao mercado. Seguindo as tendências mundiais de sustentabilidade a Dalila tem também produtos ecologicamente corretos, cujos materiais são fabricados visando reduzir o uso de recursos naturais como água e energia.

Bom, eu acho que cada um aqui dentro da Dalila, pelo menos o que a gente quer, é que pense na Dalila como algo muito grande para cada um, então se a pessoa seja lá da produção, seja líder, quer que a Dalila melhore, quer que a Dalila esteja bem no mercado ela tem que procurar inovação, em pequenos detalhes, seja no dia a dia em coisas que melhorem o processo produtivo seja em coisas que sejam apresentadas para o mercado de uma maneira diferente (Responsável de atendimento e comercialização).

- Construção de lealdade dos clientes: a empresa dedica o atendimento acolhedor, a criação compartilhada e as convenções, para integrar os clientes e construir lealdade, mas principalmente mediante o compromisso com a qualidade dos produtos e a resolução de problemas de clientes. Além disso, a empresa possui uma estratégia corporativa de manutenção e bom relacionamento com seus clientes, interagindo com eles nas datas importantes. Assim, a filosofia da empresa com o cliente é que a relação "não é de cnpj para cnpj, mas de cpf para cpf” (Responsável de P\&D).

À Dalila eu só tenho a agradecer por tudo o que ela fez pela Biotwo até hoje, praticamente $80 \%$ do produto que é industrializado na linha de malharia, vem tudo dessa grande empresa. Assim, a nossa parceria é com relação a tudo... são pessoas e empresas assim que hoje se destacam no mercado, gente que a gente pode contar nas horas boas e ruins (Depoimento Biotwo). 
- Comprometimento da equipe em produzir o que o cliente precisa. A Dalila trabalha para satisfazer ao cliente produzindo o que ele deseja. O ambiente de proximidade que ela propicia permite uma parceria na formulação das coleções de clientes, trazendo produtos novos com o estilo ou lifestyle do consumidor final de cada parceiro, sabendo que os tecidos são todos exclusivos. Isto tem conquistado clientes, que começaram incipientemente para logo voltar-se gradativamente a um trabalho mais intenso.

Hoje eu acho que a maior vantagem do trabalho com a Dalila, além dessa proximidade que a gente tem, é toda essa reformulação que a gente fez dentro de nossa coleção, de trazer produtos com uma cara nova, mas com o estilo da Beagle, então, eu acho que o DNA da Beagle dentro da Dalila, está muito bem assertivo, a gente foge para Casa Rosa e desenvolve toda a coleção (Depoimento Beagle).

\section{c) Engajamento da liderança e equipes com a inovação}

- Monitoramento da satisfação dos funcionários com a orientação para inovação: a organização realiza pesquisas a cada três meses sobre satisfação de funcionários, sendo divulgadas as percepções sobre o andamento do trabalho e também as reclamações, tendo setores mais envolvidos que outros. No setor de criação, a geração de ideias e pesquisas novas são constantes.

- Treinamento permanente orientado a inovação: os líderes da organização incentivam a discussão sobre as necessidades de melhoria, como por exemplo, a necessidade de buscar novos fornecedores, na busca de aprendizagem de novos métodos de fiação e beneficiamento. As equipes são treinadas para ter uma visão multidisciplinar e holística da fabricação de produtos, podendo ter uma melhor visão do que precisa ser melhorado. A organização também disponibiliza treinamento externo, cujo custo é compartilhado com os funcionários.

- Integração das equipes de produção e marketing: os projetos de inovação partem geralmente da liderança da empresa, mas integram três setores: criação e relacionamento, produção e inteligência de negócio, além dos departamentos administrativo e financeiro. Os líderes de criação e design trabalharam anteriormente em produção e beneficiamento, respectivamente. Cabe ressaltar que a produção no setor têxtil, consiste da elaboração (tecelagem e/ou malharia) de tecido plano, tecidos de malha circular ou retilínea, a partir dos fios têxteis. O beneficiamento consiste na preparação dos fios para seu uso final, envolvendo tingimento, engomagem, retorção (linhas, barbantes, fios especiais, dentre outros) e tratamento especiais.

- Então ter os dois (líderes de criação e design) aqui na Casa Rosa, que eles não partiram do design, mas digamos assim que partiram do chão de fábrica, é muito bom para gente como setor, porque eles têm uma visão muito grande (Responsável de P\&D)

- Controle e monitoramento por parte da liderança: os proprietários da empresa incentivam a busca de inovação, incorporando essa característica nas lideranças de cada setor. Eles também monitoram o retorno financeiro de cada coleção, pois são conscientes da necessidade da lucratividade de cada projeto.

Os donos da empresa estão sempre de cabeça bem aberta, buscando inovação, eu acho que, não dá para dizer que eles lideram a inovação, mas eles estão sempre junto (Responsável de P\&D).

\section{Discussão}

As capacidades dinâmicas são um conjunto de processos identificáveis e específicos das organizações, que surgem influenciadas pelo dinamismo do mercado, para gerar e modificar rotinas em busca de eficiência, percebendo e aproveitando novas oportunidades que permitam reconfigurar capacidades, conhecimento e ativos tangíveis (Augier \& Teece, 2009; Eisenhardt \& Martin, 2000; Teece, 2014; Teece et al., 1997; Zollo \& Winter, 2002).

$\mathrm{Na}$ análise das capacidades dinâmicas no desenvolvimento da inovação com o intuito de criar vantagem competitiva foram evidenciados os seguintes processos (Teece, 2014) na indústria têxtil pesquisada: a) busca constante da melhor forma de selecionar clientes, de satisfazer e se antecipar as suas necessidades; b) busca de inovação e melhora em produtos, processos e práticas e; c) engajamento da liderança e equipes com a inovação.

$\mathrm{Na}$ busca permanente da melhor forma de selecionar clientes, de satisfazer e se antecipar as suas necessidades, evidenciada no caso em estudo, as organizações optam por estratégias de diferenciação focalizada, que considera que os segmentos-alvo 
devem possuir necessidades especiais incomuns, com um sistema de produção e entrega diferenciado da concorrência que atende o segmento-alvo com maior dedicação (Damanpour, 1991; Porter, 2015).

Na busca de inovação e melhora em produtos, processos e práticas para conseguir resultados, os fatores determinantes se relacionam ao fluxo de conhecimento, pois a inovação é um processo coletivo de aprendizagem de ideias novas em percurso desde o design até a produção. O treinamento disponível para os empregados, a provisão de assistência técnica aos usuários da inovação, avaliação de recompensas para uso de inovação e qualidade e acessibilidade da tecnologia determinam o processo e resultado da inovação (Van de Ven, 1986; Klein \& Knight, 2005).

Outros potenciais determinantes da inovação, como especialização, diferenciação, profissionalismo, centralização, atitude gerencial, intensidade administrativa e comunicação externa e interna, e as variáveis endógenas como capacidade para aprender, valores, interesses e poder, contribuem na transformação organizacional orientada à inovação, como visto no caso estudado (Damanpour, 1991; Christensen et al., 1998; Lam, 2005).

$\mathrm{O}$ engajamento da liderança e equipes com a inovação foi evidenciado, se relacionando com o papel dos gestores no suporte da inovação quanto à disponibilidade de recursos financeiros, treinamento, suporte e compromisso na introdução dos projetos inovadores e na orientação em longo prazo dos gestores, no encorajamento da organização para o sucesso dos projetos inovadores em nível de chefia, supervisão e grupos de trabalho, aceitando os riscos e valorizando a inovação em todos os níveis hierárquicos. (Amabile et al., 1996; Klein \& Knight, 2005). Esse comprometimento permite que a cultura de inovação se torne legítima e parte do sistema social, capaz de mudar instituições (Van de Ven, 1986)

A integração multifuncional observada no caso permite a melhora o processo de desenvolvimento de produtos, a coordenação entre áreas como P\&D, produção, marketing e outros grupos funcionais incrementa a criatividade, reduz custos e acelera o ciclo de desenvolvimento de produtos (Jassawalla \& Sashittal, 1999).

Os comportamentos colaborativos entre o fabricante e parceiros (clientes e fornecedores) acontecem quando os participantes possuem necessidades intrínsecas de experimentação e aprendizagem e concordam em uma agenda comum e abertamente compartilham desafios e poder comprometendo-se e construindo confiança mútua (Jassawalla \& Sashittal, 1999). A inovação colaborativa, evidenciada na pesquisa, se vincula também aos fornecedores, tendo efeitos positivos no comportamento dos compradores e nos resultados financeiros da parceria (Corsten \& Felde, 2005).

Finalmente, a vantagem competitiva sustentável precisa de mais que a possessão de ativos dificilmente imitáveis, mas também de capacidades dinâmicas únicas e difíceis de replicar, que possam criar, estender, atualizar, proteger e conservar a base de ativos únicos da empresa (Teece, 2007).

$\mathrm{Na}$ Figura 4, apresenta-se um resumo dos achados desta pesquisa e sua vinculação com a teoria analisada: 
Figura 4 - Identificação dos processos da Capacidade Dinâmica em conexão com a Teoria

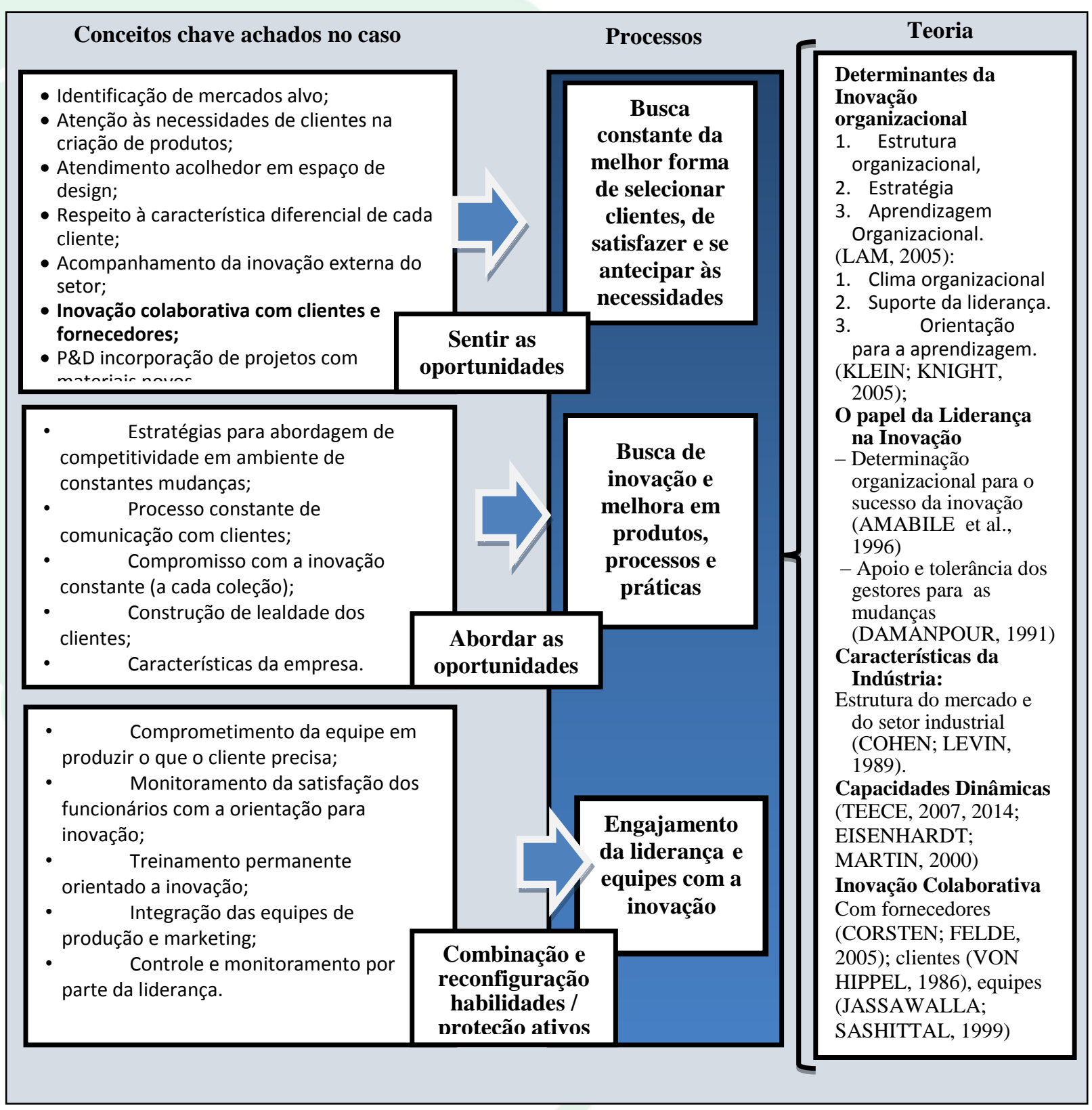

Fonte: dados da pesquisa (2017).

A Figura 4 mostra o modelo emergido da análise do caso. $\mathrm{Na}$ abordagem da inovação, identificaram-se três processos: o primeiro, a busca constante da melhor forma de selecionar clientes, de satisfazer e se antecipar as suas necessidades; 0 segundo, busca de inovação e melhora em produtos, processos e práticas e; o terceiro: engajamento da liderança e equipes com a inovação.

A busca da melhor forma de selecionar clientes, se antecipando às necessidades destes para satisfazê-los, inclui a identificação dos mercados alvo, a atenção às necessidades dos clientes na criação de produtos, o acolhimento dos clientes em espaço de criação compartilhada, o respeito das características diferenciais ou DNA de cada cliente, o acompanhamento da inovação externa do setor, tanto em tendências de moda como em tecnologia de materiais (P\&D) e equipamentos; e na inovação colaborativa com clientes e fornecedores.

O segundo momento propõe a busca permanente de inovação e melhora em produtos, processos e práticas, que inclui as estratégias de competitividade em ambientes de mudanças constantes, a comunicação contínua com clientes, o compromisso com a inovação, coleção a coleção, adaptando as características da empresa para abordar os desafios e construir a lealdade de clientes. No terceiro momento encontra-se o engajamento da liderança e equipes com a inovação, 
que inclui o comprometimento e treinamento da equipe, a integração das equipes das diversas áreas, e o controle permanente da satisfação dos funcionários e sua orientação para inovação.

Cabe ressaltar que no caso de estudo, a inovação colaborativa evidenciou-se em todo o processo de inovação, iniciando-se no processo criativo de cada coleção nos centros internacionais da moda, na seleção materiais para as novas coleções, em conjunto com os fornecedores, no design dos produtos novos, lado a lado com os clientes, até no monitoramento do comprometimento das equipes com a inovação, na integração das equipes para produzir novas ideias, novos métodos, com uma visão multidisciplinar.

A contribuição deste trabalho reside na identificação, evidenciação empírica e análise dos processos envolvidos na Capacidade Dinâmica na perspectiva da inovação, oferecendo um modelo a seguir para análise dos processos vinculados a capacidades dinâmicas, facilitando a compreensão e constatação destas. Dentre as limitações da pesquisa estão a própria seleção do caso e dos respondentes, que foi de modo intencional e a impossibilidade de generalização dos achados, por tratar-se de pesquisa qualitativa com uso de evidências recolhidas de estudo de caso (Eisenhardt, 1989; Yin, 2015). Futuras pesquisas podem se focar em diferentes tipos de indústria ou se valer de outras lentes teóricas.

\section{CONSIDERAÇÕES FINAIS}

A Teoria das Capacidades Dinâmicas permite às empresas modificar e reconfigurar recursos, evoluindo constantemente em um ambiente de mudanças frequentes, sustentando a vantagem competitiva que diferencia à empresa de outras organizações (Augier \& Teece, 2009; Eisenhardt \& Martin, 2000; Teece et al., 1997; Zollo \& Winter, 2002). A revisão da literatura indica que o fluxo de capacidades dinâmicas se alimenta de três componentes: 1) Sentir as necessidades do mercado detectando oportunidades, 2) Abordar as oportunidades e 3) Reconfigurar recursos e processos.

$\mathrm{Na}$ busca constante da melhor forma de selecionar clientes, de satisfazer e se antecipar as suas necessidades, evidenciada no caso em estudo, a organização optou pela estratégia de diferenciação focalizada, na qual considera que os segmentos-alvo devem possuir necessidades especiais incomuns, com um sistema de produção e entrega diferenciado da concorrência que atende o segmento-alvo com maior dedicação (Damanpour, 1991; Porter, 2015).

Na busca de inovação e melhora em produtos, processos e práticas para conseguir resultados, os fatores determinantes se relacionam ao treinamento disponível para os empregados, a provisão de assistência técnica aos usuários da inovação, avaliação de recompensas para uso de inovação e qualidade e acessibilidade da tecnologia (Klein \& Knight, 2005; Van de Ven, 1986).

$\mathrm{O}$ engajamento da liderança e equipes com a inovação, observado no caso, se relaciona como papel dos gestores no suporte da inovação quanto à disponibilidade de recursos financeiros, treinamento, suporte e comprometimento com os projetos inovadores e com a orientação em longo prazo dos gestores, o encorajamento da organização para o sucesso dos projetos inovadores em nível de chefia, supervisão e grupos de trabalho, aceitando os riscos e valorizando a inovação em todos os níveis hierárquicos (Amabile et al., 1996; Klein \& Knight, 2005).

$\mathrm{O}$ estudo mostrou que a estratégia baseada nas capacidades dinâmicas explica como é possível sustentar a vantagem competitiva no setor têxtil, estabelecendo um ciclo contínuo com orientação para a inovação colaborativa e dinâmica de produtos e capacidades inovadoras envolvendo o fabricante, os seus fornecedores e clientes.

Nota: As autoras desejam manifestar seu agradecimento à Coordenação de Aperfeiçoamento de Pessoal de Nivel Superior (CAPES) pelo apoio recebido para a realização desta pesquisa. 


\section{REFERÊNCIAS}

Aarts, B., \& Bauer, M. (2002). A construçao do corpus: um princípio para a coleta de dados qualitativos. In Pesquisa Qualitativa com Texto, Imagem e Som: Um manual prático. Petrópolis: Editora Vozes.

Adner, R., \& Helfat, C. E. (2003). Corporate effects and dynamic managerial capabilities. Strategic Management Journal, 24(10), 1011-1025.

Allen, T. J. (1971). Communications, technology transfer, and the role of technical gatekeeper. $R \& D$ Management, 1(1), 14-21.

Amabile, T. M., Conti, R., Coon, H., Lazenby, J., \& Herron, M. (1996). Assessing the work environment for creativity. Academy of Management Journal, 39(5), 1154-1184. http://doi.org/doi: 10.2307/256995

Augier, M., \& Teece, D. J. (2009). Dynamic capabilities and the role of managers in business strategy and economic performance. Organization Science, 20(2), 410-421.

Baldwin, C., \& Von Hippel, E. (2011). Modeling a paradigm shift: From producer innovation to user and open collaborative innovation. Organization Science, 22(6), 1399-1417.

Barney, J. (1991). Firm resources and sustained competitive advantage. Journal of Management, 17(1), 99-120.

Bernard, H. R., \& Gravlee, C. C. (2014). Handbook of methods in cultural anthropology. Rowman \& Littlefield.

Blau, J. R., Mckinley, W., \& Blau, J. R. (2008). Ideas, Complexity, and Innovation, 24(2), 200-219.

Brown, S., \& Eisenhardt, K. (1995). Product Development: Past Research, Present Findings and Future Directions. The Academy of Management Review, 20(2), 343-378. http://doi.org/10.5465/AMR.1995.9507312922

Calamel, L., Defélix, C., Picq, T., \& Retour, D. (2012). Inter-organisational projects in French innovation clusters: The construction of collaboration. International Journal of Project Management, 30(1), $\quad$ 48-59. http://doi.org/10.1016/j.ijproman.2011.03.001

Christensen, C., Craig, T., \& Hart, S. (2001). The great disruption.

Christensen, C. M., Suárez, F. F., \& Utterback, J. M.
(1998). Strategies for survival in fast-changing industries. Management Science, 44(12-NaN-2), S207-S220.

Corsten, D., \& Felde, J. (2005). Exploring the performance effects of key-supplier collaboration: an empirical investigation into Swiss buyer-supplier relationships. International Journal of Physical Distribution \& Logistics Management, 35(6), 445461.

Crossan, M. M., \& Apaydin, M. (2010). A multidimensional framework of organizational innovation: A systematic review of the literature. Journal of Management Studies, 47(6), 1154-1191. http://doi.org/10.1111/j.1467-6486.2009.00880.x

Dalila Têxtil. (2017). Site Institucional. Retrieved from http://www.dalilatextil.com.br/

Damanpour, F. (1991). Organizational innovation: A meta-analysis of effects of determinants and moderators. Academy of Management Journal, 34(3), 555-590. http://doi.org/10.2307/256406

Eggers, F., \& Kraus, S. (2012). Growing Young SMEs in Hard Economic Times: The Impact of Entrepreneurial and Customer Orientations - A Qualitative Study from Silicon Valley, 24(1), 99111. http://doi.org/10.1080/08276331.2011.10593528

Eisenhardt, K. (1989). Building theories from case study research. Academy of Management Review, 14(4), 532-550.

Eisenhardt, K., \& Martin, A. J. (2000). Dynamic capabilities: what are they? Strategic Management Journal, $\quad 21, \quad 1105-1121$. http://doi.org/10.1002/10970266(200010/11)21:10/11<1105::AIDSMJ133>3.0.CO;2-E

Flick, U. (2009). Introdução à Pesquisa Qualitativa. (Artmed, Ed.) (3.). Porto Alegre: Artmed.

Guest, G. (2014). Sampling and selecting participants in field research. Handbook of Methods in Cultural Anthropology. Rowman \& Littlefield, Lanham, MD, USA, 215-249.

Hult, G. T. M., Hurley, R. F., \& Knight, G. A. (2004). Innovativeness: Its antecedents and impact on business performance. Industrial Marketing Management, 33(5), 429-438. http://doi.org/10.1016/j.indmarman.2003.08.015

Jassawalla, A. R., \& Sashittal, H. C. (1999). Building collaborative cross-functional new product teams. 
Academy of Management Perspectives, 13(3), 5063. http://doi.org/10.5465/AME.1999.2210314

Katz, R., \& Tushman, M. (1981). An investigation into the managerial roles and career paths of gatekeepers and project supervisors in a major $\mathrm{R} \&$ $\mathrm{D}$ facility. $R \& D$ Management, 11(3), 103-110.

Klein, K. J., \& Knight, A. P. (2005). Innovation implementation: Overcoming the challenge. Current Directions in Psychological Science, 14(5), 243-246.

Lam, A. (2004). Organizational Innovation. In J. Fagerberg, M. David, \& R. R. Nelson (Eds.), Handbook of Innovation. Oxford University Press. http://doi.org/10.5897/JAERD12.088

Maykut, P., \& Morehouse, R. (2002). Beginning Qualitative Research: A Philosophical and Practical Guide. Taylor \& Francis. Retrieved from https://books.google.com.br/books?id=61L4DTHaT soC

Nieves, J., \& Haller, S. (2014). Building dynamic capabilities through knowledge resources. Tourism Management, 40, 224-232.

Nonaka, I. (2008). The knowledge-creating company. Boston: Harvard Business Review Press.

Pavlou, P. A., \& El Sawy, O. A. (2011). Understanding the elusive black box of dynamic capabilities. Decision Sciences, 42(1), 239-273.

Porter, M. E. (2015). Estrategia Competitiva: Técnicas para el análisis de los sectores industriales y de la competencia. Grupo Editorial Patria.

Prahalad, C. K., \& Hamel, G. (2006). The core competence of the corporation. In Strategische unternehmungsplanung-strategische unternehmungsführung (pp. 275-292). Springer.

Rumelt, R. P., Schendel, D., \& Teece, D. J. (1994). Fundamental issues in strategy: A research agenda. Boston: Harvard Business Press.

Saenz, M., \& Revilla, E. (2014). Absorptive Capacity in Buyer-supplier Relationships: Empirical Evidence of Its Mediating Role, 50(April), 18-40. http://doi.org/10.1111/jscm.12020

Schumpeter, J. a. (1961). Capitalismo, Socialismo e Democracia. (E. F. de Cultura, Ed.), Editado por George Allen e Unwin Ltd. Rio de Janeiro: Editora Fundo de Cultura. http://doi.org/10.2307/2549943

SEBRAE. (2016). Critérios de Classificação de
Empresas: ME-MEI-EPP 2016. Retrieved January 1, 2017, from http://www.sebraesc.com.br/leis/default.asp?vcdtexto $=4154$

SINTEX. (2015). Sindicato das indústrias de fiação, tecelagem e do vestuário de Blumenau. Indústria Têxtil de Santa Catarina, Perspectivas e Desafios para o Crescimento. Retrieved May 20, 2017, from http://www.sintex.org.br/arquivos/249_ap_sintex2015_final.pdf

Subramaniam, M., \& Youndt, M. A. (2005). The influence of intellectual capital on the types of innovative capabilities. Academy of Management Journal, 48(3), 450-463.

Teece, D. J. (2007). Explicating dynamic capabilities: the nature and microfoundations of (sustainable) enterprise performance. Strategic Management Journal, 28(13), 1319-1350.

Teece, D. J. (2014). The foundations of enterprise performance: Dynamic and ordinary capabilities in an (economic) theory of firms. The Academy of Management Perspectives, 28(4), 328-352.

Teece, D. J., Pisano, G., \& Shuen, A. (1997). Dynamic Capabilities and Strategic Management. Strategic Management Journal, 18(7), 509-533.

Trotter, R. T. (2012). Qualitative research sample design and sample size: Resolving and unresolved issues and inferential imperatives. Preventive Medicine, 55(5), 398-400.

Van de Ven, A. H. (1986). Central problems in the management of innovation. Management Science, 32(5), 590-607.

Verona, G., \& Ravasi, D. (2003). Unbundling dynamic capabilities: an exploratory study of continuous product innovation. Industrial and Corporate Change, 12(3), 577-606.

Volberda, H., Van Den Bosch, F., \& Mihalache, O. (2014). Advancing management innovation: Synthesizing processes, levels of analysis, and change agents. Organization Studies, 35(9), 12451264. http://doi.org/10.1177/0170840614546155

Von Hippel, E. (1986). Lead users: a source of novel product concepts. Management Science, 32(7), 791-805.

Yin, R. K. (2015). Estudo de Caso-: Planejamento e Métodos. Bookman editora.

Zhuang, L. (1995). Bridging the gap between technology and business strategy: A pilot study on 
the innovation process. Management Decision, $33(8)$,

http://doi.org/10.1108/00251749510093897
Zollo, M., \& Winter, S. G. (2002). Deliberate learning and the evolution of dynamic capabilities. Organization Science, 13(3), 339-351. 


\section{APÊNDICE}

\section{Roteiro de Entrevista Semiestruturada}

I. Sentir o mercado e detectar oportunidades - Processo de inovação

1. Como surgem as ideias e projetos inovadores?

2. Existe alguma divisão continua que procure projetos de melhoria contínua? P\&D? Quais suas funções e prerrogativas?

3. Em geral, quais têm sido os últimos projetos de inovação?

4. Quem e como se seleciona as novas tecnologias? E os fornecedores para essa?

5. Envolvimento dos funcionários. Quanto estão eles envolvidos nos processos de inovação?

6. Vocês monitoram a inovação externa à companhia? Como?

7. Vocês percebem mudanças na tecnologia no setor industrial?

8. Vocês nota mudanças significativas na concorrência? Produtos? Preços? Qualidade? Outros?

II. Abordar oportunidades - Clientes / Mercados

9. Qual o processo para identificação de mercados alvo?

10. Como vocês escutam seus clientes?

11. Tem havido mudanças importantes nas preferências dos clientes? Quais?

12. Vocês acham que as necessidades dos clientes podem ser mudadas? Como?

13. Como vocês conseguem manter a lealdade dos seus clientes?

\section{Combinação e Reconfiguração de Capacidades - Liderança, Governança e Conhecimento}

14. Qual o papel da liderança na busca de inovação? Nos últimos 5,10 ou mais anos.

15. Existem pressões para ter retornos financeiros no curto prazo?

16. Qual o foco de desenvolvimento de líderes futuros na sua divisão / na empresa?

17. A forma de decidir é descentralizada?

18. Qual o escopo do controle?

19. Qual a política de treinamento da empresa?

20. Vocês monitoram as atitudes dos funcionários quanto a satisfação? De que forma?

Acatada a observação do avaliador A.

Não se precisa explicar a teoria dos métodos. 